\title{
The Hidden Sex: Representations of Intersex People in Circus and Sideshow Novels
}

\author{
NAOMI FRISBY, Sheffield Hallam University
}

\begin{abstract}
Despite being the hidden sex in society, intersex people with ambiguous genitalia are visible in a number of circus and sideshow novels. These characters are often used as plot devices, performing a stable gender identity whilst concealing their intersex status for the sake of the plot. They are portrayed as deceptive and licentious, their identities placing them outside of the sex and gender binaries and leaving them dehumanised. It is only in Pantomime by Laura Lam that the possibility of an alternative portrayal is glimpsed, although questions regarding the sex and gender binaries and non-normative sexuality remain.
\end{abstract}

\section{KEYWORDS}

Intersex, Gender, Performativity, Sexuality, Literature

\section{Introduction}

The US publishing industry came under scrutiny in 2015 due its failure to offer a true reflection of the society in which we live. A 'Diversity Baseline Survey' (2015) conducted by the publisher Lee \& Low Books sought to explain why, in the past twenty years, the number of diverse books published in the USA never exceeded an average of $10 \%$. The authors of the survey drew a correlation between the high percentage of white (80), cis (98.7), heterosexual (88.2), non-disabled (92.8) people working in the publishing industry and the lack of broad representation in published books.

One genre in which we might expect to find a diverse range of characters is circus and sideshow literature. The circus has been seen as a safe space for those who fall outside of mainstream society, particularly those with non-normative bodies ${ }^{1}$. However, the desire to create a narrative that maintains a mainstream reader's interest and provides a shocking denouement means writers often use marginalised people to provide entertainment.

Three American contemporary circus novels include intersex characters who are key to the plot: The Bearded Lady by Sharlee Dieguez (1999) tells the story of Jess who, after the deaths of her parents, runs away and joins the circus. There she meets equestrian Marion Des Cartes and falls in love. The Transformation of Bartholomew Fortuno by Ellen Bryson (2010) is set in a fictionalised version of P.T. Barnum's

1 The reasons for this are beyond the scope of this paper. 
American Museum. Bartholomew Fortuno tells the story of bearded lady Iell Adams' time there. Finally, Pantomime by Laura Lam (2013) is set in the $107^{\text {th }}$ Century in a pseudo-Victorian society. Iphigenia Laurus runs away from home and hides in the circus as Micah Grey. While the reader knows that Iphigenia/Micah is intersex, the majority of the characters do not.

\section{Sex and Gender}

A baby has no sex prior to the moment the midwife declares, 'It's a girl/boy'. A binary sex classification is bestowed upon the child following sight of the baby's genitals. That a child is assigned a sex this way is problematic for two reasons: one, biological sex is also determined by chromosomes and hormones. This means a number of intersex conditions go unidentified and can cause problems later in life: during puberty when their biological sex appears to change, or in adulthood when they are deemed infertile. Secondly, many societies continue to dictate that there are only two sex classifications in humans: male and female. This leads to babies who are born identifiably intersex, classified by their genitalia, forced to undergo 'corrective' gender surgery, often within twenty-four hours of their birth.

Intersex is an umbrella term for a number of conditions that signify a variation from the binary male or female body. Accord Alliance ${ }^{2}$ define intersex as 'congenital conditions in which development of chromosomal, gonadal, or anatomic sex is atypical' (2016). They list eighteen conditions that cover ambiguous genitalia and a range of hormone and chromosome variations. Inevitably this means there is no consensus as to the number of people who are intersex. U.S. specialists estimate that a baby with genitals ambiguous enough not to identify with either binary sex constitutes 1 in 2000 live births. (Accord Alliance 2016) However, Blackless et al. (2000) conclude that the number of live births which 'do not conform to a Platonic ideal of absolute sex chromosome, gonadal, genital and hormonal dimorphism' ${ }^{3}$ (151) is $1.7 \%$. This suggests that the sex binary is a construction which excludes $1.7 \%$ of the population, rendering them either invisible or subject to medical intervention in order to conform to norms even medical professionals recognise as unachievable.

While those with ambiguous genitals account for only a small number of the intersex population, all three of the novels named above focus on characters with ambiguous genitalia. It is possible that the reason for this is that, according to Ward Hall's 'King

2 Accord Alliance replaced the Intersex Society of North America in March 2008.

3 'With respect to sex chromosome composition, gonadal structure, hormone levels, and the structure of the internal genitalia [...] we generally consider Homo sapiens to be absolutely dimorphic. Biologists and medical scientists recognise, of course, that absolute dimorphism is a Platonic ideal not actually achieved in the natural world. Nonetheless, the normative nature of medical science uses as an assumption, the proposition that for each sex there is a single, correct developmental pathway. Medical scientists, therefore, define as abnormal any deviation from bimodally distributed genitalia or chromosomal composition.' (Conte and Grumbach 1989) (Blackless et al. 2000, 151). 
of the Sideshow', "'the greatest attraction for the blow-off was a half-and-half”, (Mannix 1976, 64). However, in all of these novels, the characters' intersex condition is hidden from those around them.

Despite the fact that sex and gender are not synonymous, wider society often regards them as such. This provides further complications for intersex people.

Judith Butler defines gender as 'the repeated stylisation of the body, a set of repeated acts within a highly rigid regulatory frame that congeal over time to produce the appearance of substance, of a natural sort of being' $(1999,45)$. This suggests that it is possible for an intersex person to appear as one gender 'on the surface of the body' (1999, 185). However, Butler argues that 'certain kinds of gendered expressions [are] found to be false and derivative, and others, true and original' (1999, viii). The question for intersex people is who makes the decisions as to what a true gender expression is for someone who does not conform to the sex binary. Currently this appears to be their parents and medical professionals at the behest of society. In terms of novels, this status is given to the author who can choose either to reflect society or to question it.

Butler uses a discussion about drag to reframe gender and demonstrate the falsity of the gender binary:

But we are actually in the presence of three contingent dimensions of significant corporeality: anatomical sex, gender identity, and gender performance. If the anatomy of the performer is already distinct from the gender of the performance, then the performance suggests a dissonance not only between sex and performance, but sex and gender, and gender and performance $(1999,187)$.

As we shall see, this distinction also applies to people with ambiguous genitalia, further exemplifying that the gender binary is a societal construction.

\section{The History of Intersex People in the USA}

Elizabeth Reiz (2009) offers an account of the history of intersex people in the USA, including the first explicit case of an individual with ambiguous genitalia in American legal history. In 1629, Thomas/Thomasine Hall was brought before the court for 'dressing in women's apparel' $(2009,10)$. Hall's description of their life in which they moved from a male gender identity to wearing 'woemans apparel' $(2009,11)$ and then back to the masculine again, would concur with modern definitions of a gender fluid identity. When the court agreed that Hall's sexual characteristics marked them as both male and female, '[i]t decreed that henceforth s/he be required to wear a paradoxical costume consisting of "mans apparel, only his head to be attired in a Coyfe and Crossclothe with an Apron before him”' $(2009,12)$. The court, therefore, considered 
particular items of clothing to identify the anatomy beneath them. Their ruling condemns Thomas/Thomasine to wear a combination of what the court deems to be male and female clothing.

There is a crossover here with Butler's use of drag as an illusion of gender identity. She comments on how an individual's clothing choices can give us an 'erroneous' (1999, xxiv) cultural reading of the anatomy beneath. The punishment given to Hall for daring to live as a gender fluid person was to ensure that their clothing did highlight their anatomical variation. This ruling was no doubt made to humiliate Hall and prevent them from forming intimate relations with males or females.

Reiz also details the legalities for intersex people in eighteenth-century America. These included whether they 'should be given a male or female name at birth to whether or not a hermaphrodite should be allowed to marry or divorce' $(2009,10)$. The emphasis was on them to choose one sex. Reiz draws links between 'increasing geographic mobility and urbanization and new impersonal commercial networks' (2009, 30) and the idea of someone with ambiguous genitalia as 'repulsive and duplicitous' (2009, 24). Gender fluidity was not an option that society was willing to accept.

\section{Representations of Intersex People with Ambiguous Genitalia in Circus Novels}

In both The Bearded Lady and The Transformation of Bartholomew Fortuno, the identities of Marion Des Cartes and Iell Adams are hidden from the reader and the novels' protagonists. In both instances, their gender performance encourages us to read the characters' genders as female.

[Marion] was a perfectly formed, tall, ethereal angel of a being in a flashing silver vest and riding skirt. She had luminous skin and dark silken hair radiating in waves to her shoulders. Her eyes were steely and hypnotic. This fiery angelic apparition would have continued to hold the girls spellbound had she remained silent, but her low baritone voice popped the tenuous bubble of illusion (Dieguez 1999, 59).

Dieguez initially describes Marion as an archetype of feminine beauty, focusing on her skin, hair and eyes, but then goes on to state that her voice prevents her from being the heavenly creature the narrator, Jessie, and her sister, Tweets, believed her to be. Throughout the first third of the novel, Marion is repeatedly described as beautiful, 'the object of many men's fantasies' $(1999,104)$ but there are two suggestions she is not able to fully perform as a woman: the first is the description of her hands, twice within four pages, as 'large' and 'strong and rather large for a woman' (1999, 60, 63). It is implied that her hands, and therefore Marion, are 
powerful and this is not a trait aligned with femininity. The second refers to the way she walks:

It seemed to Jessie that Marion walked as though she were nude. She didn't fuss with clothes the way other women did. She didn't lift the hem of her skirt to step over obstacles, but strode blithely, expecting her vestments to flow with her like the servants they were. An artist...Jessie concluded admiringly $(1999,86)$.

Dieguez has Jessie refer to Marion as 'an artist' when she, unbeknownst to Jessie, is performing her gender and, in terms of societal standards and expectations, failing. In Jessie's eyes, the exception raises her status, leaving no scope for questioning her identity. Butler argues that the occasional discontinuity of the repeated acts which give the illusion of a stable gender identity 'reveal the temporal and contingent groundlessness' of this identity $(1999,192)$. The combination of the way Marion walks, her hands and her voice, guides the reader to read Marion as potentially male. Despite the novel being set in a circus, where the 'hermaphrodite' was a popular sideshow exhibit, it is unlikely the reader would make the assumption that Marion is an intersex person.

Throughout the history of Western philosophy, only men have been awarded universal status, women have been designated a position in relation to this. Butler argues that this leads to the conclusion that 'one is one's gender to the extent that one is not the other gender, a formulation that presupposes and enforces the restriction of gender within that binary pair' $(1999,30)$. With this cultural background brought to the text by the reader, there are only two possibilities for Miriam's physical identity: she must either be a woman with some traits that would be read as masculine or a man disguised as a woman, performing (and occasionally failing) a female gender identity.

Iell Adams' first full appearance in The Transformation of Bartholomew Fortuno is via a portrait of her that Bartholomew Fortuno finds in the bowels of P. T. Barnum's American Museum.

She was stunning, simply stunning. Her face, her skin, her bright hair: all beautiful. But most stunning of all? She sported the most astonishing beard I had ever set eyes upon. Fire-red and passionate, it erupted from her face like an uncaged animal, roaming over voluminous breasts and reaching out at the ends like the tentacles of some man-eating primordial beast. I'd seen bearded women before, of course, heavy-featured women cursed with thick arms and chins buried beneath an outbreak of unseemly hair - the effect more like a man in a dress. But this! Her sea-coloured cape draped across one shoulder and the other was bare, its skin porcelain white. Her eyes were deep green, and they gazed imperiously down an aquiline nose as if in challenge to the entire world of men. (Bryson 2010, 56-57) 
Like Marion, Iell's skin, hair and eyes are highlighted for their beauty. Bartholomew, and therefore the reader, also reads Iell as female due to her 'voluminous breasts' and his suggestion that, despite her beard which would be read as masculine within the gender binary, she looks utterly feminine. The comparison to other bearded ladies he has encountered reinforces this reading.

The difference between the portrayal of Iell Adams and that of Marion Des Cartes is partially due to the narrative perspective. The Bearded Lady is told in third person subjective from the point of view of Jessie. Although this suggests that the reader's perspective will converge with that of the protagonist, it leaves scope for authorial comment. The Transformation of Bartholomew Fortuno is in first person from the protagonist's viewpoint. This leaves the reader purely with the view that Bartholomew holds, one which, for the majority of the book, is blinded by love. There is only one point where it is suggested that Iell may be anything other than feminine and that occurs during a conversation in her quarters where she stands behind a chair, 'resting her elbows on the backrest, tilting forward like a man'. The point where Bartholomew realises that Iell might not be who he thinks she is occurs when he is presented with a portfolio of photographs of her in which she has posed in a number of provocative positions.

How comfortable she'd looked. As if she'd been caught unawares in her natural state. She had posed, hadn't she? What was I thinking? She wasn't comfortable. She was an actress. A performer. That look had been faked. (Bryson 2010, 240)

Miriam is 'an artist', Iell is an 'actress' and 'performer'. Here, however, Bartholomew sees the performance as consolidation of her femininity. It is not an aberration in the sense that it brings Iell's gender performance into question, instead it leaves the narrator questioning her virtue, another societal condition of women.

Both Dieguez and Ellen Bryson are guilty of dehumanising Marion and Iell. This is prominently displayed at the climax to each novel where the intersex nature of the characters is revealed: they are used as plot devices to provide a twist in the tale. The revelations of the characters' false gender identities also illustrates Reiz's comments about hermaphrodites being regarded as 'duplicitous' $(2009,24)$ in the eighteenth and nineteenth centuries. This is sharply illustrated in Jessie's reaction to the revelation that Marion is intersex: 'This was not the perfect Marion that Jessie had so adored[...]This Marion wasn't even ordinary; this person was a sham, a liar, and a whimpering freak, as ugly... as ugly as...' (Dieguez 1999, 286). Dieguez's vocabulary choices - 'sham', 'liar' - emphasise the idea of intersex people being deceitful. This is further supported by Marion's admission that she is on the run from the FBI, wanted for the murder of a soldier she killed in revenge for her brother's death. The 
authorities are looking for a man as, despite her mother's attempts to make her wear a dress, Marion identified as male from a young age.

However, Tweets' reaction to the revelation introduces the possibility of an alternative viewpoint: 'What a stroke of luck; Marion could be a boy or a girl with a mere change of clothes. Think of the trouble she could get into if she cared to take advantage' (Dieguez 1999, 296). Even though this is a positive reaction, once again the idea of deception is present. Through Tweets' perception, however, this becomes exciting and playful; if Tweets represents a younger generation this could suggest that acceptance is possible although not unproblematic.

Bryson reveals Iell's sex to both Fortuno and the reader when the former sneaks into a private viewing Iell has been forced to perform by Barnum.

Her other sex, as real and large as my own, eased out languidly from between her legs as she slipped a long slender finger into her orifice in proof that the he was also a she. I reeled with the fact of it. A gift like none I have ever seen. Magnificent. Utterly horrible. Not only woman, but man as well. $(2010,317)$

The scene is salacious, crude and designed to provoke revulsion in the reader. Again, the reader is guided to believe that intersex people are dishonest and deceptive, although the disgust combined with awe which Bartholomew Fortuno greets the revelation with demonstrates one reason why an intersex person might feel compelled or even condemned to hide their status. This is compounded by Fortuno's lack of vocabulary to describe Iell: he can only refer to her within the confines of the sex and gender binaries.

In contrast to these two portrayals, Pantomime (Lam 2013) has been praised by reviewers from the LGBTIQ communities for its portrayal of an intersex teenager ${ }^{4}$. It is revealed to the reader early in the narrative that Micah Grey/Iphigenia Laurus ${ }^{5}$ is intersex. The use of a pseudo-Victorian society in the $107^{\text {th }}$ century seems to demonstrate that society's views of ambiguous genitalia are outdated. This leads us to reflect on our own society, finding much about which to be critical.

Iphigenia becomes Micah and runs away from home after her parents receive an offer of marriage for her and decide she must have 'corrective' surgery in order for the marriage to have any chance of success. Lam puts forward both sides of the gender argument: Iphigenia's father says, 'Perhaps Iphigenia was meant to be masculine

4 https://ladygeekgirl.wordpress.com/2015/06/28/book-review-pantomime-by-laura-lam/. Accessed $21^{\text {st }}$ August 2016; http://www.onceuponabookcase.co.uk/2013/07/review-pantomime-by-lauralam.html. Accessed 21 $1^{\text {st }}$ August 2016; http://www.gayya.org/?p=1334. Accessed 21 $1^{\text {st }}$ August 2016 5 Lam uses he/she pronouns as the character changes identity. For continuity, I will follow the same pattern. 
rather than feminine, or somewhere in the middle' (2013, 201-2). Here there is a suggestion that a spectrum of gender might be a possibility. However, he then goes on to refer to Iphigenia's intersex status as a 'condition'. Her mother expands on this:

A condition that now has a cure[...]Iphigenia can become a girl. Only a girl. Doctor Ambrose is positive that the surgery would be successful. She'd have a bit of scarring, but he says it would be minimal. Between that and some daily medication, she would be female. $(2013,203)$

The idea that being intersex is a condition for which there is a cure suggests that it is still seen as a medical disorder, due to the fact that it does not conform to the binaries of sex and gender, which remain unbroken in this society.

Again, her father defends her, suggesting that this would remove half of who she is and that she is too fond of 'boyish things' to 'ever be wholly female' (2013, 203). Eventually he relents when her mother suggests this is what's best for her: she needs to marry for the family's status in society. Here Iphigenia is twice erased: as an intersex person and then as a woman, a bride, a gift connecting two families' lineage. Iphigenia's own thoughts on overhearing the conversation support the idea of her being dehumanised: 'I did not like what I was, but I liked this proposed cure even less' (2013, 203). The words Lam chooses emphasise her distance her from her own body: she sounds as though she is describing an object or a thing, not her own person.

Once Iphigenia runs away and disguises herself as Micah, he says, 'At least in the circus I had the freedom to be myself' $(2013,102)$. Taken alone this line seems to suggest that this person has accepted who they are and can live freely as an intersex person. However, this line needs to be taken in the context of those prior to it:

Perhaps my running away would have proven to my parents that I would not allow them to change my life and they would leave me be.

Leave me to be a spinster, tolerated in society but always just outside of it, pitied and always under my parents' roof. And if they died before me, I would be a burden on Cyril. As a Laurus, I would have no way to support myself through employment, unless I became a governess or turned to writing or teaching, neither of which I thought would be my true calling. At least in the circus I had the freedom to be myself. $(2013,102)$

It is clear that Micah still sees himself as an outsider, someone who would be tolerated but never accepted. Although he describes himself as free in the circus he still hides the fact he is intersex, binding his breasts and telling no one of his true identity. Part of the reason for this is that he is on the run, his parents have a detective looking for him, and once again an intersex person in a circus novel is linked to 
deception. The other part of the reason, however, is that even in the circus, he feels he wouldn't be accepted.

Like the other two novels, Pantomime also contains an instance of the protagonist as actor/performer but because Lam does not use her protagonist's sex as a plot device, she is able to explore ideas of gender performativity more explicitly. When the circus company within which Iphigenia is hidden as Micah, the trapeze artist, decide to perform the classic romance Leander \& Iona, Micah finds himself playing the female lead. His love interest, Aenea, describes him as 'a prettier girl than I am!' (2013, 349) and Dryston, the clown, tells him 'you look and sound a little too believable as a woman' (2013, 355). Lam highlights that Iphigenia/Micah performs both as a female and a male.

If Butler's comments with regards to drag are transposed to intersex people and Iphigenia/Micah specifically, Lam uses the distinction of anatomy and gender to demonstrate that an intersex person's anatomy can be both simultaneously synonymous and distinct from their gender performance depending how their gender is read by others. Lam moves the discussion beyond this, demonstrating the instability of both the sex and gender binaries. This is where Pantomime differs from the other two novels: where their portrayal of an intersex character is managed within the confines of the gender binary, using it as a plot device in order to produce a climactic revelation, Lam breaks the binary demonstrating that an intersex person can be gender fluid. If their only choice is to perform as male or female, then that decision should be made according to which gender they feel most comfortable as, or even which gender they feel most comfortable as at any particular moment; there is no requirement beyond societal control and normative structures that necessitates a person to maintain a stable gender identity.

Again, as in the other novels, there is a climactic moment when Micah reveals he is intersex. Unable to articulate who he is, Micah removes his clothing to reveal his breasts and genitals. In this instance, the reveal does not involve the reader, it is directed to Aenea, the trapeze artist with whom Micah has been having a romantic relationship and Dryston who, through his own class-based deception, has become a reluctant friend to Micah. Like Jessie and Bartholomew, Aenea rejects Micah, feeling that she has been deceived. Again, Lam links intersex with deception. However, the novel ends with Dryston and Micah teaming up: 'You're strange, and there's no denying that. But I'm strange as well, and most certainly more monstrous than you' (2013, 388). Lam offers hope for intersex people to be accepted by others; however, Dryston is also an outsider and it is acceptance on the terms that they both reside beyond gender, class and sexual normative boundaries.

\section{Sexuality and the Heterosexual Reinforcement of the Gender Binary}


In the 1999 edition of Gender Trouble, Butler concedes 'that the performance of gender subversion can indicate nothing about sexuality or sexual practice' (xiv). However, it is impossible to address the treatment and representation of intersex people without recourse to the socially constructed link between sexuality and social status.

Sigmund Freud's reference to anyone not strictly heterosexual as an 'invert' (1987, 46-47) and his three classifications for people's behaviour established homosexuals in opposition to the desired norm while his attempts to explain homosexuality through the lens of apparently gendered behaviour and/or as a result of conditions of upbringing only served to cement heterosexuality as the only acceptable expression of sexuality.

The creation of a homosexual identity places anyone identifying as such as 'other' and therefore in opposition to dominant society. This dominant, heterosexual, society then functions in order to maintain the alleged disparities in sex and gender. Butler states that identities 'in which gender does not follow from sex and those in which the practices of desire do not "follow" from either sex or gender' (25) cannot exist in this type of society. We have already seen that this is true for intersex people with regards to their gender following from their sex. It is also true in terms of their sexuality.

In the case of the aforementioned Thomas/Thomasine Hall, Reiz declares that the court's ruling that Hall should wear a combination of what was regarded to be masculine and feminine garments was done to prevent them from seducing 'the unwary of either sex, should s/he attempt to do so, and then to have coitus with the “wrong” sex' (2009, 12). For a person with two sets of functioning genitalia, who is of 'the wrong sex'? A person of ambiguous genitals could be classified as either/both heterosexual/homosexual depending on their gender identity and the society in which they live. Reiz goes on to say that the by the late eighteenth/early nineteenth centuries in America, hermaphrodites were suspected of promiscuity due to medical reports which stated that those examined were capable of and reportedly did engage in sexual intercourse with both sexes.

It is a short step from those thoughts to the erasure of intersex people and this has been achieved through corrective surgery, declarations of sex on the birth certificate and the proliferation of the gender binary. This has helped to maintain the patriarchal, heterosexual status quo, designating those who refuse to conform as 'other' and 'unnatural'.

In The Bearded Lady, Jessie supresses her feelings for Marion when she believes she is falling in love with her. Dieguez describes her as feeling 'longing, fear, and shame' (1999, 191). Jessie's overriding wish for a heteronormative relationship is expressed in her attempts to replace Marion's face in her subconscious with 'the more seemly image of a man's' $(1999,191)$. Not a specific man, any man is preferable to a desire 
for a woman. When Marion's intersex nature is revealed, Jessie rejects her and Marion leaves the circus. However, at the end of the novel, they are reconciled via a letter, an invitation for Jessie to join Marion in Paris. Dieguez relates a fantasy of Jessie's to the reader where she and Marion are at the beach where they play naked in the water before having sex on the sand. Although female pronouns are still used, the naked, intersex, Marion is described by Jessie as 'the most beautiful being [she] had ever seen' and the final words of the book are 'the truly loved' (1999, 307-8) suggesting that a life outside of the gender binary and heternormativity is possible. However, Marion's true identity remains hidden from society and the book ends without an indication of whether her seemingly homosexual relationship with Jessie will be accepted by Parisian society. She may be visible to Jessie but it appears that the double erasure of Marion's identity by society will continue.

Iell has a more adverse ending with regards to her sexuality in The Transformation of Bartholomew Fortuno. Two-thirds of the way into the novel, she clearly rejects Emma Swan, the giantess. ${ }^{6}$ Swan not only loves Iell, she knows that Iell is intersex and accepts her wholeheartedly: 'I love every single part of you however strange' (Bryson 2010, 186), although her use of the word 'strange' positions Iell's anatomy against the normative. Iell rejects Emma's advances with a clear and simple, 'I’m sorry' (Bryson 2010, 186). Bryson rejects the idea of sexual promiscuity for Iell and also shows that she does not hide her identity from Emma. As far as the reader and Fortuno are concerned, Iell conforms to the gender binary and the heterosexual norm. Later, Iell reveals she was married, her husband beating her almost to death on their wedding night upon first sight of her anatomy. The previously besotted Fortuno also rejects her once he has seen her genitalia. He offers her the possibility of a life together but refers to her 'peculiarities' and 'that' (2010, 323), suggesting that her real identity can be erased living as a heterosexual couple, conforming to the gender binary, outwardly, at least. Iell herself makes reference to wanting 'to live a normal life' $(2010,323)$ but knows it is impossible. In order for Iell to be accepted, Bryson only allows her the option of a relationship with Emma Swan. This appears to mirror the relationship Jessie and Marion have at the end of The Bearded Lady but while Jessie seems to accept Marion as intersex, Emma makes clear to Fortuno that her preference is for men. Iell's rejection of Emma suggests that Iell will not erase her chosen identity by either appearing as a man in a heterosexual relationship or identifying as bisexual and thereby erasing her sexuality as well as her sex and gender. Paradoxically however, by doing so Bryson still further highlights Iell as 'other', fashioning her identity against the universal masculine as opposed to embracing it.

Iphigenia Laurus from Pantomime is the only one of the three intersex characters to disguise themselves as male rather than female. As female, Iphigenia is vulnerable both to a marriage and to surgery she does not want. This choice prevents her erasure in one sense, at least temporarily, as she appears as the universal gender, free to exist

6 This character is based on Anna Swan, the giantess, who did reside at the American Museum. There is no explanation as to why Bryson has changed her forename but not her family name. 
and move about the world unquestioned. Again, despite the praise Pantomime has garnered from the LGBTIQ communities, Lam conceives Iphigenia/Micah's relationships firmly within the heternormative, at least in appearance. Before Iphigenia runs away from home, she plays a game of hide and seek with her brother and his friends. Hidden in a tree with Damien, he kisses her. She intends to push him away after a minute but his hand goes beneath her petticoats and between her legs. She senses his horror. “"Please...” I whispered, hoarsely. "I was...born with-” “A prick.” His voice was flat, surprised and cruel.' She goes on to say that she will never forget that he 'recoiled in revulsion' (2013, 89-90). While Iphigenia does not question her sexuality while being raised as female, when she chooses the masculine identity of Micah and begins a relationship with Aenea, the trapeze artist, he asks, '... would I be a girl kissing her, or a boy?' (2013, 193). Here Lam deviates both from society’s heterosexual norm and that of the other books. She is the only author of the three to question an alternative to a sexual binary that marks heterosexuality as the norm and homosexuality as other. Whilst the possibility of someone gender fluid freely existing in circus literature remains unfulfilled, Lam does at least posit the possibility of an alternative sex and sexual identity.

\section{Conclusion}

I have argued that the novels cited fail to provide a representative and, therefore, diverse portrait of intersex people. A focus on people with ambiguous genitalia would fit a traditional circus theme if it were used to create a 'half-man, half-woman' exhibit. However, through making these intersex characters plot devices, Dieguez and Bryson dehumanise them, forcing them into the sex and gender binaries created by their societies, using their sexuality to mark them as 'other' and reinforcing the view that those with ambiguous genitalia are duplicitous. Lam's gender fluid protagonist, partially created to support teenagers wanting to explore their own gender identity (Lam, 2015), offers some hope that gender fluidity is possible. However, the reactions from other characters illustrate opinions held in our society. This could support teenagers dealing with similar issues but also show that wholesale acceptance is unlikely.

One of the key problems with the small number of portrayals of intersex people in literature is that these few representations become universal depictions. Even in novels set in the circus and sideshow, places outside of dominant societal norms, intersex characters are viewed at best as outsiders and at worst as deceptive, licentious beings. By attempting to position them against the binaries of sex and gender and, therefore, heterosexual norms, using them as plot devices rather than portrayals of human beings, writers continue to erase intersex people, dehumanising them and marking them firmly as 'other'. In order to accurately represent intersex communities, writers of circus and sideshow novels need to provide a wider range of portrayals of intersex characters, further considering ideas of gender fluidity and the language they 
use to illustrate these characters. This way, writers will support the inclusion of intersex people in society as a whole.

\section{References}

Blackness, M., Charuvastra, A., Derryck, A., Fausto-Sterling, A., Lauzanne, K. and Lee, E., (2000). 'How Sexually Dimorphic Are We? Review and Synthesis', American Journal of Human Biology, 12(2), 151-166

Bryson, E. (2010) The Transformation of Bartholomew Fortuno, London: Picador

Butler, J. (1999) Gender Trouble (Second Edition), New York: Routledge

Dieguez, S. (1999) The Bearded Lady, Georgia: Hill Street Press

Freud, S. (1987) On Sexuality, London: Penguin Books

Irigaray, L. (1985) This Sex Which Is Not One New York: Cornell University Press

Lam, L. (2013) Pantomime, Nottingham: Strange Chemistry

Lam, L. (2015) 'Ask Me Anything' [online] 10 June. Available at http://lauraroselam.tumblr.com/post/121192090380/i-have-to-say-i-love-yourbook-pantomime-and-your. Accessed 21 ${ }^{\text {st }}$ August 2016.

Low, J. (2016) 'Where Is the Diversity in Publishing? The 2015 Diversity Baseline Survey Results' [online] 26 January. Available at http://blog.leeandlow.com/2016/01/26/where-is-the-diversity-in-publishing-the2015-diversity-baseline-survey-results/. Accessed ${ }^{\text {th }}$ April 2017.

Mannix, D.P. (1976) Freaks: We Who Are Not as Others, Hong Kong: Pocket Books

Reiz, E. (2009) Bodies in Doubt: An American History of Intersex, Baltimore: The Johns Hopkins University Press

Wittig, M. (1992) The Straight Mind and Other Essays, Boston: Beacon Press

Naomi Frisby is $\mathrm{PhD}$ candidate in creative writing at Sheffield Hallam University. She is writing a speculative fiction novel set around a sideshow. Her thesis, Female Freaks and Feminism: Gender and Representation in Circus and Sideshow Literature, considers the portrayal of bodies read as female in the context of the sideshow and the impact this has on wider society. Her short stories have been shortlisted for The White Review Short Story Prize and longlisted for the Manchester Fiction Prize. She blogs about female writers at https://thewritesofwoman.com and has also written for Fiction Uncovered, Waterstones' blog and Tilted Axis Press' blog. She can be found on Twitter@Frizbot.

Email: Naomi.R.Frisby@student.shu.ac.uk 